\title{
"As leis não bastam, os lírios não nascem da lei "': IPTU progressivo no tempo como possibilidade de efetivação da função social da propriedade no Brasil
}

"Laws are not enough, lilies do not arise from law": timing-progressive property tax as an effective possibility for the social function of property in Brazil

André Felipe Bandeira Cavalcante[a] (ㄷ) Érica Milena Carvalho Guimarães Leôncio[a] (1)

[a] Universidade Federal do Rio Grande do Norte (UFRN), Programa de Pós-graduação em Estudos Urbanos e Regionais (PPGEUR), Natal, RN, Brasil

Como citar: Cavalcante, A. F. B., \& Leôncio, É. M. C. G. (2019). “As leis não bastam, os lírios não nascem da lei ": IPTU progressivo no tempo como possibilidade de efetivação da função social da propriedade no Brasil. urbe. Revista Brasileira de Gestão Urbana, 11, e20180015. https://doi.org/10.1590/2175-3369.011.001.A008

\section{Resumo}

A questão habitacional no Brasil vem sendo tratada de forma isolada. No entanto, deve ser compreendida como questão social e analisada na totalidade. A função social da propriedade enquanto conquista histórica pode ser utilizada visando ao enfrentamento dessa pauta. Entretanto, assiste-se nas cidades ao agravamento desse contexto. Nesse sentido, é trazido um breve apontamento sobre os dados recentes do déficit habitacional e seus determinantes sociais, assim como um registro dos chamados vazios urbanos e sua relação com o processo de especulação imobiliária nas cidades brasileiras, entendendo, dessa forma, como a retenção de terra urbana vem sendo abordada no país. 0 presente artigo pretende reunir aspectos que problematizem a função social da propriedade e o acesso aos direitos e às políticas públicas habitacionais no cenário brasileiro, bem como analisar o IPTU progressivo, entendendo-o como uma opção para além da função fiscal nas cidades e como um instrumento do direito urbanístico na efetivação de direitos, de gestão da cidade e do uso e da ocupação do solo urbano.

Palavras-chave: Questão habitacional. IPTU progressivo. Função social da propriedade.

\section{Abstract}

The housing issue in Brazil has been treated as an isolated problem. However, it must be understood as a social question, and analyzed in its totality. The social function of property as a historical achievement can be implemented to face this agenda. However, we've been witnessing the aggravation of this problem in the cities. Thus, we discuss an appointment about the recent data of the housing inequality and its social determinants, understanding how the urban land retention is being addressed in Brazil. This article intends to assemble aspects that problematize both the social function of the property, and the access to the rights and public housing policies in Brazil. We also aim to analyze Timing-Progressive

\footnotetext{
1 Trecho da poesia "Nosso Tempo", de Carlos Drummond de Andrade. Faz parte do livro "A Rosa do Povo", escrito durante a II Guerra Mundial e publicado em 1945 (Andrade, 2000).
} 
Property Tax, which is not only understood as an option beyond the cities taxing function but also as an instrument of Urban Law in rights attainment, of city management and use and occupation of urban land.

Keywords: Housing issue. Timing-progressive property tax. Social function of the property.

\section{Introdução}

Classifiquei a favela de quarto de despejo porque em 1948, quando o Dr. Prestes Maia começou a urbanizar a cidade de São Paulo, os pobres que habitavam os porões foram atirados ao relento (Jesus, 1961, p. 181).

Esse trecho anterior utilizado retrata a violência do processo de urbanização no Brasil. Dessa forma, a pesquisa traz apontamentos importantes, utilizando recortes históricos e realçando fatos que são necessários para compreender como a luta por moradia no país não é recente. Na Declaração Universal dos Direitos Humanos (ONU, 1948), em seu artigo XXV, tem-se a inclusão do direito à habitação. E existe a reprodução de um conceito ideológico de "problema habitacional" com uma conotação de que ele sempre existiu e nunca mudará.

O filósofo Karl Marx (1991) critica também em sua obra a tentativa de justificar que a renda fundiária existe para poder ser comprada e vendida, porque se estaria buscando justificar sua existência com a própria existência.

0 "problema" da habitação pensada dessa forma acaba mascarando, distorcendo e escondendo as verdades sobre essa questão. Fica parecendo que é algo muito complexo e difícil de solucionar, e a burguesia, utilizando o Estado, claro, procura mostrar que tenta fazer de tudo para diminuir o "problema".

Para Gabriel Bolaffi (1976), a ideologia mascara os problemas reais e os substitui pelos falsos problemas, uma vez que não são formulados conforme suas características intrínsecas. Ao contrário, formulam-se problemas sem a pretensão de resolvê-los, para legitimar o poder e para que sejam tomadas medidas para satisfazer outros propósitos. Isso não quer dizer que o problema não exista, mas que a burguesia não utiliza os termos corretos ou teria de reconhecer que não possui capacidade para resolvê-lo.

Como Engels destaca em "Para a Questão da Habitação", quando trata de como a burguesia encaminha essa pauta:

Está claro como a luz do sol que o Estado atual não pode nem quer remediar o flagelo da falta de moradias. 0 Estado nada mais é que a totalidade do poder organizado das classes possuidoras, dos proprietários de terras e dos capitalistas em confronto com as classes espoliadas, os agricultores e os trabalhadores. 0 que não querem os capitalistas individuais tampouco quer o seu Estado. Portanto, embora individualmente o capitalista lamente a escassez de moradia, dificilmente mexerá um dedo para dissimular mesmo que superficialmente suas consequências mais terríveis, e o capitalista global, o Estado também não fará mais do que isso. Quando muito tomará providências para que o grau de dissimulação superficial que se tornou usual seja aplicado em toda parte do mesmo modo (Engels, 1887, p. 39).

Engels (2012, p. 222) explica que, "quanto mais progride a civilização, mais se vê obrigada a encobrir os males que traz necessariamente consigo, ocultando-os com o manto da caridade, enfeitando-os ou simplesmente negando-os". Portanto, a burguesia se utiliza da ideologia enquanto estratégia para se livrar de uma solução da questão. É possível ver essa reprodução ser difundida pelos aparelhos ideológicos controlados pela burguesia, como a mídia, o judiciário, a Igreja, as escolas e o próprio Estado.

Existem ainda questões estruturais que impedem o modo de produção capitalista de oferecer habitação para todos. Segundo Villaça (1986, p. 7) e Lima (2003, p. 19), a habitação é vinculada ao solo. Portanto, essa característica impossibilita que seja produzida em pouco espaço e depois distribuída. Ainda, existe a dificuldade da produção em larga escala, assim como o obstáculo da propriedade privada, que transforma o preço do produto habitação muito oneroso e acaba por segregar as 
populações mais pobres em localizações sem infraestrutura e distante dos grandes centros, sobretudo, de trabalho.

A questão sobre a habitação popular no Brasil passa a se constituir na segunda metade do século XIX, com foco na Lei de Terras (Lei $n^{\circ} 601$, de 18 de setembro de 1850), da mesma forma que se desenvolveu na Inglaterra no século anterior. Segundo Villaça $(1986$, p.14), começa a surgir aqui o "homem livre", que, antes de qualquer coisa, é um despejado das suas terras com o processo de expropriação e grilagem, despejado de seu trabalho e dos meios de vida. Tanto os brasileiros quanto os estrangeiros são despejados das decadentes fazendas de café, da Itália ou das senzalas. São os "ninguéns" do escritor uruguaio Eduardo Galeano (2002, p.42). Tem-se o problema da habitação enquanto questão social.

0 déficit habitacional se insere no conceito mais amplo de necessidades habitacionais ao incluir ainda as situações que apontam as moradias inadequadas. E para a Fundação João Pinheiro, responsável pelos cálculos do déficit habitacional desde 1995

[...] como déficit habitacional entende-se a noção mais imediata e intuitiva de necessidade de construção de novas moradias para a solução de problemas sociais e específicos de habitação detectados em certo número (FJP, 2015, p. 93).

Em estudo recente sobre a estimativa do déficit habitacional para 2013 e 2014, o déficit em 2013 correspondia a 5,846 milhões de domicílios, dos quais 5,010 milhões, ou 85,7\%, estavam localizados nas áreas urbanas. No ano de 2014, percebeu-se aumento do déficit habitacional, perfazendo um total de 6,068 milhões de unidades. Já quanto ao estoque de domicílios particulares permanentes e improvisados do Brasil, o percentual se manteve em $9 \%$.

As faltas de planejamento urbano e regional, de uma reforma fundiária e da democratização do uso e da ocupação do solo são questões que agravaram as contradições que se manifestam no território dos centros urbanos brasileiros. Assim, a questão habitacional é uma questão social que se relaciona com o processo de especulação imobiliária e retenção de terras. Portanto, torna-se essencial entender o conceito de vazio urbano e sua relação com a disputa na cidade.

\section{"Enquanto morar for um privilégio2": da especulação imobiliária aos vazios urbanos nas cidades brasileiras}

O estudo sobre as políticas habitacionais tem se tornado urgente nas gestões e nos órgãos do Estado, sendo, portanto, indispensável. A problemática aqui analisada vem se agudizando devido à população que se concentra cada vez mais nas áreas urbanas ${ }^{3}$. Fica nítida a necessidade do Estado enquanto provedor de políticas. Nesse sentido, Valença $(2014$, p. 346) destaca:

Num país com tamanha extensão territorial, porém totalmente "loteado", até mesmo a terra pública é gerida segundo a lógica do mercado. Ou seja, os governos federal, estaduais e municipais não destinam seus terrenos de melhor localização, considerados "nobres", para moradia ou outra utilização social. A lógica do mercado fundiário é a da valorização imobiliária ("especulação"): o foco é a renda, não o lucro industrial. A propriedade privada da terra confere poderes infindáveis a quem a possui, com isso determinando uma utilização pulverizada no espaço e no tempo, com muitos vazios urbanos. 0 controle do uso do solo, quando há, é feito de forma pouco eficiente. Por estes e outros motivos, a questão fundiária é considerada o "nó" da política urbana nacional,

Como Borde ressalta (2004, p. 1), não se utiliza o conceito de vazio urbano para áreas verdes, praças, espaços de sociabilidade ou áreas desocupadas da periferia que se constituem áreas de expansão da cidade. No entanto, os espaços residuais, gerados pelo processo capitalista de construção e

\footnotetext{
2 "Enquanto morar for um privilégio, ocupar é um direito" é uma frase de autoria desconhecida muito utilizada pelos movimentos sociais urbanos de luta por moradia.

${ }^{3}$ Segundo o censo (IBGE, 2010), 84,35\% da população vivia em áreas consideradas urbanas.
} 
reconstrução permanente da cidade, que se expressam em um vazio a preencher de informação e de novos usos, e os lugares, os territórios e os edifícios em situação de esvaziamento, como espaços abandonados, ruínas, terrenos baldios, terrenos subutilizados e imóveis ociosos, qualificam-se com a dupla dimensão vazio e urbano (Morales, 1996). Ainda de acordo com Borde (2004, p. 1), o que faz deles vazios urbanos são os aspectos formal, funcional, simbólico e político diretamente relacionados à condição urbana.

Desde que o arquiteto Solá-Morales (2002) apresentou sua visão ampla sobre o termo, considera-se que são os espaços esquecidos e degenerados da cidade, mas que apresentam oportunidades para reutilização e revitalização. A partir de análise baseada em fotografias de terrenos abandonados e vazios da década de 1970, definiu-se vazio urbano utilizando o termo "Terrain Vague", palavras de origem francesa com definições ambíguas, tal como o termo em português (Silva, 2014, p. 18).

Há, portanto, o vazio como ausência, mas, ao mesmo tempo, como espaço do possível, da promessa, da expectativa. Os dados sobre imóveis urbanos descrevem essa cidade cheia de vazios, inclusive nas regiões próximas ao centro da cidade. Áreas que se encontram à espera de uma verdadeira utilização. Para Souza (2010), os vazios configuram-se em espaços de oportunidade de mudanças, porque podem constituir-se em espaços desocupados e prontos para serem reutilizados, seja para reconstrução de um imóvel existente (imóvel não utilizado), seja para construção de um novo imóvel (terreno baldio).

Como Alvarez (1994, p. 2) defende, "não se pode falar em uma cidade que possui duas partes, uma construída e outra vazia, pois ambas fazem parte do mesmo processo de reprodução do espaço". Por isso, faz-se central compreender como esse conceito teórico se manifesta na prática do cotidiano. Morgado (2005, p. 285) caracteriza como espaços de caráter expectante, não ocupados, que permanecem sem uso, mesmo com as potencialidades que apresentam, como acesso privilegiado, devido às redes de infraestrutura e com valor determinado em função de uma valorização imobiliária possível.

Como contribuição para a relação entre os espaços que não cumprem a função social enquanto elemento especulativo, Kowarick (1993) defende que esses vazios apresentam um papel essencial para esse processo nas cidades, porque favorecem a especulação que tem levado o setor imobiliário a ocupar terrenos, mantendo áreas próximas ao núcleo central à espera de valorização. No entanto, as zonas mais distantes, sem infraestrutura, sobretudo, têm servido como forma de aquisição para as classes populares.

A retenção de terreno urbano, sobretudo daqueles servidos por infraestrutura, leva a população excluída a ocupar áreas inadequadas para moradia ou regiões de proteção ambiental, como mananciais, mangues, dunas no litoral, e terras ambientalmente frágeis, como beira de córregos, encostas íngremes e deslizantes. É possível ver como resultado o processo de exclusão da população mais pobre do acesso ao solo urbanizado (Maricato, 2000, p. 152-165), assim como existe um custo pela manutenção de infraestrutura, paga por toda população, que, devido à capacidade contributiva, acaba pesando mais no bolso das classes de menor poder aquisitivo. Como afirma Singer:

A cidade capitalista não tem lugar para os pobres. A propriedade privada do solo urbano faz com que a posse de uma renda monetária seja requisito indispensável à ocupação do espaço urbano. Mas o funcionamento normal da economia capitalista não assegura o mínimo de renda a todos. Antes pelo contrário, este funcionamento tende a manter uma parte da força de trabalho em reserva, o que significa que uma parte correspondente não tem meios para pagar pelo direito de ocupar um pedaço do solo urbano (Singer, 1982, p. 33).

Portanto, a manutenção de terrenos e de espaços vazios à espera de melhores oportunidades para realização de renda é central no entendimento dessa temática relacionada à questão habitacional brasileira. É necessário debater também o papel do Estado nesse processo, tendo em vista que as cidades brasileiras cresceram de forma. 0 que prevalece é a busca de interesses individuais e privados em detrimento do interesse público. Vê-se um "planejamento urbano para alguns, mercado para alguns, leis para alguns, modernidade para alguns, cidadania para alguns" (Maricato, 2000, p. 125).

É urgente a efetivação de um planejamento dos vazios, assim como é necessário o combate aos mecanismos de retenção de terra urbana, o que acaba por impedir a inclusão social. Vale lembrar, conforme Maricato (2000, p. 124), que os problemas urbanos e sociais das cidades não ocorrem 
exatamente por falta de planos urbanísticos, mas pelo fato de esses planos serem aprovados conforme interesses da política local tradicional, do capital imobiliário e das empreiteiras.

Por isso, deve ser papel do Estado a regulação dos mercados imobiliários, promovendo políticas públicas que atendam a fatores que possam:

reduzir os custos de produção como também do acesso à moradia; desenvolvendo políticas de controle e concessão de crédito para viabilizar a atividade imobiliária (capital de giro) e o consumo (demanda/financiamento a longo prazo); desenvolvendo políticas de investimento público no setor para favorecimento dos mais pobres; promovendo o desenvolvimento tecnológico do setor de construção civil e produção de materiais; procurando exercer controle sobre o preço da terra, resgatando parcial ou totalmente a renda da terra, produto do trabalho social, apropriada pelo proprietário(e para isso podem ser utilizados os impostos sobre o terreno e a edificação, sobre a renda, etc.); promovendo o emprego e a renda, incrementando o poder de compra (Valença, 2003, p. 169-170).

Pode-se considerar a especulação imobiliária como sendo "uma forma pela qual os proprietários de terra recebem uma renda transferida dos outros setores produtivos da economia, especialmente através de investimentos públicos na infraestrutura e serviços urbanos" (Campos, 2001, p. 48). Portanto, trata-se de uma distribuição coletiva dos custos da melhoria das localizações e uma apropriação privada dos lucros provenientes dessas melhorias.

\section{Análise sobre a função social da propriedade urbana no Brasil}

O instituto da função social da propriedade surgiu da ideia de que esta, por ser fonte de produção e riqueza, deveria ser disciplinada pelo Estado, como forma de garantir as necessidades da sociedade. Ao analisar o instituto da função social da propriedade, Fachin (1988) ensina que a função social se relaciona com o uso da propriedade, sendo o modo como são exercitados as faculdades ou os poderes inerentes ao direito de propriedade. 0 autor deixa claro o entendimento de que a propriedade está diretamente ligada ao uso a que se propõe, tendo o proprietário poder/dever de dar-lhe uma destinação social, respeitar a legislação vigente e os interesses comuns da sociedade na qual se encontra.

No ordenamento jurídico brasileiro, a referência ao cumprimento da função social da propriedade surgiu pela primeira vez na Constituição de 1934 (Brasil, 1934), a qual garantia o direito à propriedade, desde que não fosse exercido contra o interesse social ou coletivo. Mas somente com a promulgação da Carta Magna de 1988 (Brasil, 1988) a função social da propriedade passou a ser considerada como elemento condicionante ao exercício da propriedade, sendo inserida no Título dos Direitos e Garantias Fundamentais (art. 5o , XXIII). Além disso, adquiriu status de princípio da ordem constitucional econômica (art. 170, III), da política urbana (art. 182) e da política agrícola e fundiária (art. 184 e 186).

A inclusão no texto constitucional de um capítulo específico para a política urbana, com instrumentos voltados à garantia da função social da cidade e da propriedade urbana, no âmbito de cada município, partiu da luta de um movimento multissetorial e nacional pela reforma urbana, iniciado nos anos de 1960 (Rolnik, 2002).

Segundo Ribeiro \& Cardoso (2003), a reforma urbana teria como principal objetivo a instituição de um novo padrão de política pública com as seguintes orientações:

a) instituição da gestão democrática da cidade, com a finalidade de ampliar o espaço de exercício da cidadania e aumentar a eficácia/eficiência da ação governamental;

b) fortalecimento da regulação pública do uso do solo urbano, com a introdução de novos instrumentos de política fundiária (solo criado, imposto progressivo sobre a propriedade, usucapião especial urbano, etc) que garantam o funcionamento do mercado de terras condizente com os princípios da função social da propriedade imobiliária e da justa distribuição dos custos e benefícios da urbanização; 
c) inversão de prioridades no tocante à política de investimentos urbanos que favoreça as necessidades coletivas de consumo das camadas populares, submetidas a uma situação de extrema desigualdade social em razão da espoliação urbana (Ribeiro \& Cardoso, 2003, p. 104).

Nesse contexto, o art. 182, §2º, da Constituição Federal, vincula a propriedade urbana à sua função social de ordenação da cidade. A literatura explica que, conforme as normas dos artigos 182 e 183,

A propriedade urbana é formada e condicionada pelo direito urbanístico a fim de cumprir sua função social específica: realizar as chamadas funções urbanísticas de propiciar habitação (moradia), condições adequadas de trabalho, recreação e circulação humana; realizar em suma, as funções sociais da cidade (Silva, 2010, p. 75).

Para assegurar a adequada utilização dos imóveis e o combate ao uso especulativo do solo urbano por meio dos planos diretores, a Constituição Federal trouxe alguns mecanismos de efetivação da função social da propriedade urbana, quais sejam:

\section{Art. 182.[...]}

$\S 4^{\circ}$. É facultado ao Poder Público Municipal, mediante lei específica para área incluída no plano diretor, exigir, nos termos da lei federal, do proprietário do solo urbano não edificado, subutilizado ou não utilizado, que promova o seu adequado aproveitamento, sob pena sucessivamente de:

I - parcelamento ou edificação compulsórios;

II - imposto sobre a propriedade predial e territorial urbana progressivo no tempo;

III - desapropriação com pagamento mediante títulos da dívida pública de emissão previamente aprovada pelo Senado Federal, com prazo de resgate de até dez anos, em parcelas anuais, iguais e sucessivas, assegurados o valor real da indenização e os juros legais (Brasil, 1988).

Em que pese o estabelecimento da função social da propriedade urbana e dos mecanismos para sua efetivação, a Constituição de 1988 não determinou parâmetros explícitos para caracterizar o seu cumprimento, deixando essa tarefa a cargo do legislador municipal por meio da edição de planos diretores e leis específicas. Além disso, o legislador constitucional previu no artigo citado a necessidade de uma lei federal que definisse as diretrizes gerais pertinentes à matéria, somente vindo a ter concretude com o advento do Estatuto da Cidade (Brasil, 2011), o qual estabelece regras gerais e determina que os prazos e as condições para implementação estejam previstos em legislação específica, aplicando-se em áreas previamente determinadas no plano diretor (Carvalho, 2009).

Os instrumentos previstos na Constituição (Brasil, 1988) e no Estatuto da Cidade (Brasil, 2001), conforme afirma a literatura, possuem o objetivo de "induzir a ocupação de áreas já dotadas de infraestrutura e equipamentos, mais aptas para urbanizar ou povoar", o que contribui para evitar a expansão horizontal da cidade para áreas sem infraestrutura ou ambientalmente frágeis; para fazer o correto uso de terrenos vazios dentro da malha urbana, que já são beneficiados pelos investimentos públicos, não servindo apenas à especulação imobiliária; e para "aumentar a oferta de terra e de edificação para atender à demanda existente", de forma a garantir oportunidade de moradia nas regiões centrais, possibilitando que os cidadãos não sejam obrigados a morar em áreas desprovidas de infraestrutura (Rolnik, 2002, p. 63).

\section{O IPTU progressivo no tempo como instrumento de efetivação da função social da propriedade}

Na hipocrisia de fazer o contrário do que dizem (isto é, dizer que vão realizar a justiça, nas normas, enquanto resguardam os seus privilégios) os dominantes se contradizem, deixando buracos, por onde os juristas de vanguarda podem enfiar a alavanca do progresso (Lyra, 1982, p. 54). 


\section{Em relação ao IPTU progressivo no tempo, Saule \& Rolnik afirmam que:}

Pelo artigo 7ํㅜ do Estatuto da Cidade, em caso de descumprimento das condições e dos prazos previstos para o parcelamento ou edificação nos termos da lei municipal específica, o Município deve aplicar o imposto sobre a propriedade predial e territorial urbana (IPTU) progressivo no tempo, mediante a majoração da alíquota pelo prazo de cinco anos consecutivos (Saule \& Rolnik, 2001, p. 25).

Além da finalidade fiscal - arrecadar recursos financeiros para custear as despesas públicas -, o IPTU se destaca da maioria dos outros tributos em razão da sua extrafiscalidade, pois o imposto está diretamente ligado à promoção do ordenamento territorial e do desenvolvimento urbano, sendo utilizado, segundo a literatura, para "evitar a ociosidade da terra urbanizada, recuperar as mais valias produzidas por investimentos públicos, mitigar a informalidade, legitimar a posse quando viável e universalizar a provisão de recursos públicos" (Cesare et al., 2015, p. 18).

Assim, ao fazer uso da função extrafiscal do IPTU, o custo da retenção da terra ociosa aumenta, reduzindo o retorno econômico da especulação imobiliária e, consequentemente, liberando a terra para ser devidamente ocupada.

De acordo com o princípio do benefício, o IPTU pode ser graduado conforme os benefícios urbanos (serviços públicos e infraestrutura) providos pelo município. Além disso, o imposto atua também na promoção da cidadania, "na medida em que alerta para a responsabilidade dos cidadãos com o financiamento dos gastos públicos", sendo apelidado de "Condomínio da Cidade" no gibi "Jacinto Bené Fício e o Imposto Predial e Territorial Urbano - IPTU", publicado pelo Ministério das Cidades, pelo Lincoln Institute of Land Policy e pela Caixa Econômica Federal (Cesare et al., 2015, p. 19).

Apesar de, no Brasil, o IPTU ainda ser utilizado preponderantemente como um imposto fiscal, observa-se que, no cenário internacional, a função extrafiscal do IPTU vem sendo cada vez mais importante para a chamada justiça social, garantindo "acesso à habitação com bens e serviços urbanos satisfatórios e cuidados com o meio ambiente", tendo como fatores determinantes para torná-lo um instrumento de justiça social: estimular a ocupação ordenada das áreas urbanas, ser um instrumento de redução da carência de habitação em áreas com infraestrutura urbana e auxiliar, com outros tributos, a recuperação da valorização dos imóveis resultante do investimento público em infraestrutura (Matijascic, 2009, p. 20).

Referindo-se aos citados mecanismos, Silva (2014, p. 3) afirma que incorporá-los ao ordenamento jurídico não quer dizer que possuam efetividade, pois "muitos desses instrumentos foram inseridos nos planos diretores sem o devido cuidado jurídico e urbanístico que garanta sua aplicação em curto tempo". Os principais obstáculos percebidos são "a ausência de regulamentações ou critérios objetivos que permitam sua utilização no controle sobre o uso do solo e no combate à especulação fundiária". Embora a obrigatoriedade de cumprimento da função social da propriedade urbana esteja prevista no texto constitucional desde sua promulgação em 1988, tendo sido regulamentada pelo Estatuto da Cidade no ano de 2001, ainda é tímida nas cidades brasileiras a aplicação dos mecanismos de efetivação.

Portanto, cabe ao Estado, principalmente, o controle sobre essa questão, regulando o uso e a ocupação do solo. A retenção de terras ociosas, além de dificultar a execução da política habitacional de amplo alcance, tendo em vista que até mesmo o Estado tem dificuldade de acesso à terra para o programa, e o alto custo da terra também resultam em uma limitação para iniciativas de implementar não apenas moradias, mas equipamentos e serviços públicos, como escolas, hospitais, parques (Maricato, 2010, p. 16).

\section{Considerações finais}

Entre os instrumentos de efetivação da função social da propriedade urbana previstos na Constituição Federal e no Estatuto das Cidades, o IPTU progressivo no tempo se mostra como um mecanismo capaz de fazer o enfrentamento ao processo de especulação imobiliária, forçando os 
proprietários dos chamados "vazios urbanos" a dar uma destinação útil aos imóveis. 0 que se pretende mostrar neste estudo é que a problemática que gira em torno da questão habitacional brasileira pode ser amenizada com a implementação dos instrumentos urbanísticos previstos na legislação e que, especificadamente, o IPTU progressivo no tempo, além de um tributo fiscal, possui, na sua função extrafiscal, potencialidade de promoção da redistribuição da terra ao coibir a estagnação de seu uso (Marinho, 2008).

No entanto, conclui-se que a mera aprovação de leis ou normas não resultará em grandes mudanças na conjuntura da questão social relacionada à moradia, e muito menos transformará radicalmente a política urbana brasileira. Assim, acredita-se que o judiciário, em regra, ignora o princípio da função social e os instrumentos urbanísticos e trata a propriedade privada como direito absoluto e dificilmente relativizado em função do que trata a Constituição Federal, o Estatuto da Cidade, os Planos Diretores e as demais normas jurídicas existentes que disciplinam o planejamento urbano, a regulação estatal e a gestão urbana do uso e da ocupação do solo.

Nesse sentido, para basilar esta conclusão, utiliza-se a análise de Maricato (2010, p. 5) quando assevera que o texto legal se caracteriza como fundamental, mas insuficiente, para resolver problemas estruturais de uma sociedade historicamente desigual, na qual os direitos não são garantidos para a maioria da população, como os direitos à cidade ou à moradia legal. Portanto, boa parte da população brasileira segue morando de forma precária e informal, no que pode ser considerado "não cidade", com ausência de equipamentos, serviços coletivos, infraestrutura; portanto, sem observância na lei ou no plano urbanístico.

Os textos normativos, em sua maioria, apresentam dispositivos bem construídos na defesa de uma cidade mais democrática, mas pode-se concluir que a aplicação dos Planos Diretores, por exemplo, segue favorecendo uns e ignorando outros. Nesse sentido, é no processo político e no controle sobre as decisões do planejamento urbano das câmaras legislativas e do poder público que se pode fortalecer a concepção da democratização do acesso à terra urbana e de uma cidade efetivamente mais justa.

\section{Referências}

Alvarez, R. (1994). Os vazios urbanos e o processo de produção da cidade (Dissertação de Mestrado). Programa de Pós-graduação em Geografia, Universidade de São Paulo, São Paulo

Andrade, C. D. (2000). Nosso tempo. In C. D. Andrade. A rosa do povo (21st ed., p. 29-29). Rio de Janeiro: Record. Bolaffi, G. (1976). Habitação e urbanismo: o problema e o falso problema. Cadernos do Centro de Estudos Rurais e Urbanos, 9, 65-85.

Borde, A. (2004). Vazios urbanos: avaliação histórica e perspectivas contemporâneas. In: Anais do VIII Seminário de História da Cidade e do Urbanismo (pp. 1-13). Niterói: Universidade Federal Fluminense.

Brasil (1934, 18 de setembro). Lei $n^{\circ}$ 601, de 18 de setembro de 1850. Brasília: Diário Oficial da União. Recuperada em 24 de setembro de 2018, de http://www.planalto.gov.br/Ccivil_03/LEIS/L0601-1850.htm

Brasil (1934, 16 de julho). Constituição da República dos Estados Unidos do Brasil de 1934. Brasília: Diário Oficial da União, seção 1, suplemento. Recuperada em 09 de julho de 2018, de

http://www2.camara.leg.br/legin/fed/consti/1930-1939/constituicao-1934-16-julho-1934-365196-

publicacaooriginal-1-pl.html

Brasil (1988, 05 de outubro). Constituição da República Federativa do Brasil. Brasília: Diário Oficial da União, seção 1. Recuperada em 09 de julho de 2018, de http://www.planalto.gov.br/ccivil_03/constituicao/constituicao.htm

Brasil (2001, 11 de julho). Lei no 10.257 de 10 de julho de 2001. Brasília: Diário Oficial Eletrônico. Recuperada em 17 de setembro de 2016, de http://www.planalto.gov.br/ccivil_03/Leis/LEIS_2001/L10257.htm

Campos, C. M., Fo. (2001). Cidades brasileiras: seu controle ou o caos (4th ed.). São Paulo: Studio Nobel.

Carvalho, J. S., Fo. (2009). Comentários ao estatuto da cidade. Rio de Janeiro: Lúmen Juris. 
Cesare, C. M., Fernandes, C. E. C., \& Baima, C. (2015) Imposto sobre a Propriedade Predial e Territorial Urbana: Caderno Técnico de Regulamentação e Implementação. Brasília: Ministério das Cidades.

Engels, F. (1887). Para a questão da habitação - Obras escolhidas em três tomos. São Paulo: Avante.

Engels, F. (2012). A origem da família, da propriedade privada e do Estado (3rd ed.). São Paulo: Expressão Popular.

Fachin, L. E. (1988). A função social da posse e a propriedade contemporânea. Porto Alegre: Editora Sérgio Antônio Fabris.

Fundação João Pinheiro - FJP. (2015). Déficit habitacional no Brasil 2011-2012. Belo Horizonte: Centro de Estatísticas e Informações.

Galeano, E. (2002). Livro dos abraços (9th ed.). Porto Alegre: L\&PM.

Instituto Brasileiro de Geografia e Estatística - IBGE. (2010). Censo 2010: população do Brasil é de 190.732.694 pessoas. Recuperada em 24 de setembro de 2018, de https://censo2010.ibge.gov.br/noticias-

censo.html?busca=1\&id=3\&idnoticia=1766\&t=censo-2010-populacao-brasil-190-732-694-pessoas\&view=noticia

Jesus, C. M. (1961). Casa de alvenaria: diário de uma ex-favelada. São Paulo: Francisco Alves.

Kowarick, L. (1993). A espoliação urbana. Rio de Janeiro: Paz e Terra.

Lima, S. L. R. (2003). A questão social, questão habitacional e sua especificidade na realidade brasileira. Rio de Janeiro: UFRJ.

Lyra, R., Fo. (1982). O que é direito (11. ed.). São Paulo: Brasiliense.

Maricato, E. (2000). As ideias fora do lugar e o lugar fora das ideias. In O. Arantes, C. Vainer \& E. Maricato (Eds.), A cidade do pensamento único: desmanchando consensos. Petrópolis: Vozes.

Maricato, E. (2010). O estatuto da cidade periférica. In C. S. Carvalho \& A. Rossbach (Org.), O estatuto da cidade: comentado. São Paulo: Ministério das Cidades.

Marinho, K. L. C. (2008). O Regime constitucional da contribuição de intervenção no domínio econômico aplicável ao setor de combustíveis (Dissertação de Mestrado). Pós-graduação em Direito Constitucional, Universidade Federal do Rio Grande do Norte, Natal.

Marx, K. (1991). O capital: crítica da economia política - livro 3: o processo global da produção capitalista (5. ed., vol. VI). Rio de Janeiro: Bertrand Brasil.

Matijascic, M. (2009). Política fiscal e justiça social no Brasil: o caso do IPTU. Brasília: IPEA. Recuperado em 01 de outubro de 2016, de

http://repositorio.ipea.gov.br/bitstream/11058/5314/1/Comunicado_n28_Pol\%C3\%ADtica.pdf

Morales, I. S. (2002). Terrain Vague. In I. S. Morales. Territorios (pp. 181-193). Barcelona: Editorial Gustavo Gilli.

Morgado, S. (2005). Protagonismo de la ausencia, interpretación urbanística de la formación metropolitana de Lisboa desde lo desocupado (Tese de Doutorado). Universidade Politécnica da Cataluña, Cataluña.

Organização das Nações Unidas - ONU. (1948). Declaração universal dos direitos humanos. Paris: Assembleia Geral das Nações Unidas. Recuperado em 02 de outubro de 2016, de http://www.dudh.org.br/wpcontent/uploads/2014/12/dudh.pdf

Ribeiro, L.C. Q., \& Cardoso, A.L. (2003). Reforma urbana e gestão democrática: promessas e desafios do estatuto da cidade. Rio de Janeiro: Revan.

Rolnik, R. (2002). Estatuto da cidade: guia para implementação pelos municípios e cidadãos - lei n. 10.257, de 10 de julho de 2001, que estabelece diretrizes gerais da política urbana (2. ed.). Brasília: Câmara dos Deputados.

Saule, N., Jr., \& Rolnik, R. (2001). Estatuto da cidade: novos horizontes para a reforma urbana. São Paulo: Pólis.

Silva, A. F. C. (2014). Preservação e instrumentos urbanísticos: os avanços e limites da transferência de potencial construtivo em Natal-RN (vol. 1). Belém: Universidade Federal do Pará.

Silva, J. A. (2010). Direito urbanístico brasileiro (6. ed.). São Paulo: Malheiros. 
Singer, P. (1982). 0 uso do solo urbano na economia capitalista. In E. Maricato (Org.), A produção capitalista da casa (e da cidade) no Brasil industrial. São Paulo: Alfa-Ômega.

Morales, I. M. (1996). Presente y futuros: la arquitectura en las ciudades. Barcelona: urbanoperú. Recuperado em 04 de julho de 2018, de http://urbanoperu.com/sites/urbanoperu.com/files/articulos/presente_y_futuros_sola.pdf

Souza, C. A. (2010). Do cheio para o vazio: metodologia e estratégia na avaliação de espaços urbanos obsoletos (Dissertação de Mestrado). Universidade Técnica de Lisboa, Lisboa.

Valença, M. M. (2003). Habitação: notas sobre a natureza de uma mercadoria peculiar. Cadernos Metrópole, (9), $165-171$.

Valença, M. M. (2014). Anotações críticas acerca da política habitacional brasileira. Natal: Editora Fórum.

Villaça, F. (1986). O que todo cidadão precisa saber sobre habitação. São Paulo: Global Editora.

Editor: Rodrigo Firmino

Recebido: Jan. 22, 2018

Aprovado: Jun. 25, 2018 